Georgia State University

ScholarWorks @ Georgia State University

\title{
Can Agent Cheap Talk Mitigate Agency Problems in the Presence of a Noisy Performance Measure? An Experimental Test in a Single- and Multi-Period Setting
}

\author{
Jeremy Douthit \\ University of Arizona, jdouthit2@email.arizona.edu \\ Linwood Kearney \\ University of North Carolina at Chapel Hill, linwood_kearney@kenan-flagler.unc.edu \\ Douglas E. Stevens \\ Georgia State University, dstevens11@gsu.edu
}

Follow this and additional works at: https://scholarworks.gsu.edu/accountancy_facpub

Part of the Accounting Commons

\section{Recommended Citation}

Douthit J, Kearney L, Stevens D. Can Agent Cheap Talk Mitigate Agency Problems in the Presence of a Noisy Performance Measure? An Experimental Test in a Single- and Multi-Period Setting. Journal Of Management Accounting Research. December 2012;24(1):135-158.

This Article is brought to you for free and open access by the School of Accountancy at ScholarWorks @ Georgia State University. It has been accepted for inclusion in Accountancy Faculty Publications by an authorized administrator of ScholarWorks @ Georgia State University. For more information, please contact scholarworks@gsu.edu. 
2012

pp. $135-158$

\title{
Can Agent Cheap Talk Mitigate Agency Problems in the Presence of a Noisy Performance Measure? An Experimental Test in a Single- and Multi-Period Setting
}

\author{
Jeremy D. Douthit \\ Florida State University \\ Linwood W. Kearney \\ Wichita State University \\ Douglas E. Stevens \\ Florida State University
}

\begin{abstract}
Given traditional agency theory assumptions and unobservable effort in a single-period setting, a moral hazard arises in which the agent is expected to shirk and provide the minimal possible effort after contracting with the principal. Traditional solutions to this agency problem include paying the agent a financial incentive tied to some noisy measure of performance or allowing the agent to develop a reputation over multiple periods. As the noisiness of the performance measure increases, however, these traditional solutions become increasingly costly and ineffective. In many single- and multiperiod agency settings in the firm, however, the agent can communicate a promised level of effort to the principal prior to contracting. We document that this pre-contract communication, which is non-enforceable and therefore considered "cheap talk" by traditional economic theory, can be highly effective in mitigating the moral hazard problem in agency theory. In a repeating single-period experimental setting where production is observable but is a very noisy indicator of effort, communication of a promised level of effort results in higher pay for the agent, higher effort, and higher expected profit for the principal than the control group. When the principal and agent interact over multiple periods, reputation building is ineffective, but cheap talk continues to yield superior outcomes. These results are consistent with recent economic theory incorporating social norms such as the norm of promise-keeping.
\end{abstract}

Keywords: agency problems; agent cheap talk; noisy performance measures; social norms; promise-keeping.

We thank Ramji Balakrishnan (editor), Geoff Sprinkle (associate editor), and two anonymous reviewers for their many helpful comments and suggestions. We also acknowledge the helpful comments of David Cooper, Greg Gerard, Bill Hillison, Mark Isaac, Lee Kersting, and workshop participants at Florida State University, Wichita State University, and the 2011 AAA Annual Meeting. We also thank Sean Collins for his programming guidance. 
Data Availability: The experimental data used in this paper are available from the authors upon request.

\section{INTRODUCTION}

$\mathrm{T}$ he most comprehensive and widely utilized theory of the firm in managerial accounting is agency theory (Baiman 1982, 1990; Lambert 2001; Brown et al. 2009). Given traditional agency theory assumptions and unobservable effort in a single-period setting, a moral hazard arises in which the agent is expected to shirk and provide the minimal possible effort after contracting with the principal (Lambert 2001; Stevens and Thevaranjan 2010). Traditional solutions to this agency problem include paying the agent a financial incentive tied to some noisy measure of performance or allowing the agent to develop a reputation over multiple periods. As the noisiness of the performance measure increases, however, these traditional solutions become increasingly costly and ineffective. Further, the complex incentive solutions required by the theory are rarely found in practice (Baiman 1990). This has caused some theorists to search for alternative solutions to the traditional agency problem that may arise endogenously within the firm, such as social norms (Fischer and Huddart 2008), moral sensitivity (Stevens and Thevaranjan 2010), and subjective performance measures (Prendergast 1999). We contribute to the literature by studying the ability of "cheap talk" on the part of the agent to mitigate agency problems in the presence of a very noisy performance measure.

In many single- and multi-period agency settings in the firm, the agent can communicate a promised level of effort to the principal prior to contracting. Traditional economic theory considers this communication cheap talk because the promised effort cannot be enforced and the principal is therefore expected to ignore it (Farrell 1987, 1993). Prior experimental studies in management accounting have demonstrated that cheap talk on the part of the principal can result in superior outcomes in a budgeting setting (Kachelmeier et al. 1994; Rankin et al. 2003). Cheap talk on the part of the agent, however, has received little attention in the literature. Given the principal-agent model in Stevens and Thevaranjan (2010) and in Bicchieri's (2006) model of social norm activation, we expect the agent's communication of a promised level of effort to activate the social norm of promise-keeping in both the agent and the principal. The activation of this social norm is expected to turn the agent's communication of promised effort from cheap talk into an effective signaling device that generates promise-keeping behavior in the agent and trusting behavior in the principal. Thus, we predict that the agent's communication of a promised level of effort will yield superior results for the agent and the firm. Using a single- and multi-period experimental setting with a very noisy performance measure, we find consistent evidence in support of our predictions.

To examine the ability of cheap talk on the part of the agent to mitigate agency problems in the firm, we use an experimental agency setting where the agent's effort is unobservable and the production outcome is observable but is a very noisy measure of effort. In this experimental setting, we manipulate the absence or presence of cheap talk and whether the principal-agent relation is single-period or multi-period. In the "no cheap talk/single-period" control condition, the agent cannot communicate a promised level of effort and interacts with a different principal each period. In the "cheap talk/single-period" condition, the agent still interacts with a different principal each period but can communicate a promised level of effort to the principal prior to contracting. In the "no cheap talk/multi-period" condition, the agent cannot communicate a promised level of effort but interacts with the same principal over all the periods in the experiment. Finally, in the "cheap talk/multi-period" condition the agent is able to communicate a promised level of effort prior to contracting and remains with the same principal over all the periods in the experiment. This $2 \times 2$ factorial design allows us to examine the effectiveness of cheap talk on the part of the agent in both a repeating single-period setting and in a multi-period setting. 
Consistent with prior experimental studies in accounting and economics (e.g., Hannan et al. 2002; Hannan 2005; Brandts and Cooper 2006, 2007), the "no cheap talk/single-period" control condition yields gift exchange behavior where principals pay higher than minimum wages to induce agents to provide higher than minimum effort, and agents on average reciprocate by providing that higher effort. When cheap talk is present, however, behavior consistent with the social norm of promise-keeping arises whereby agents promise a higher level of effort and receive a higher wage in return. In particular, wages and effort levels are significantly higher in the "cheap talk/ single-period" condition than the "no cheap talk/single-period" control condition. As expected, the very noisy performance measure creates a situation where reputation building is ineffective, and wages and effort levels are not significantly higher in the "no cheap talk/multi-period" condition than in the "no cheap talk/single-period" control condition. Nevertheless, cheap talk continues to yield superior wage and effort outcomes in the "cheap talk/multi-period" condition.

To provide direct evidence of the ability of cheap talk to mitigate agency problems in the firm, we examine the profit earned by the principal under the four experimental conditions. We find that expected firm profit is highest in the "cheap talk/single-period" and "cheap talk/multi-period" conditions, lower in the "no cheap talk/single-period" condition, and lowest in the "no cheap talk/ multi-period" condition. Thus, cheap talk on the part of the agent leads to superior outcomes for the firm. The finding that firm profit is lowest in the "no cheap talk/multi-period" condition is interesting in that it suggests that it was detrimental for the principal to attribute a positive reputation to positive outcomes in our setting with a very noisy performance measure. In an analysis of forecasts of effort by the principal, however, we find that the presence of cheap talk significantly reduces forecast error. This result suggests that principals were able to trust the communication of promised effort by the agent, consistent with the social norm of promise-keeping.

A regression analysis of the difference between promised effort and provided effort suggests that agents tended to follow through on their promised effort on average, and that deviations from promised effort were reduced by ethical concerns, the fairness of the wage, and the obligation to reciprocate with higher effort for a higher wage (Gift Exchange). Finally, a regression analysis on wages suggests that principals relied on the agent's promised effort in forming their wage offers. In summary, these results suggest that the agent's cheap talk activated the social norm of promise-keeping, which generated promise-keeping behavior in the agent, trusting behavior in the principal, and superior results for the agent and the firm.

These findings should be of interest to researchers, managers, and policy makers. Our results are consistent with recent economic theory incorporating social norms (Fischer and Huddart 2008; Stevens and Thevaranjan 2010). In their principal-agent model, for example, Stevens and Thevaranjan (2010) assume some level of moral sensitivity on the part of the agent that generates a disutility for providing less than a previously agreed-upon level of effort. The moral disutility in their model is based on the social norm of promise-keeping. Stevens and Thevaranjan (2010) allow the influence of this social norm to vary due to differences in moral sensitivity across agents, but they do not incorporate the activation of the promise-keeping norm through cues present in the contracting setting. Bicchieri's (2006) model of social norm activation suggests that the act of promise-making makes the norm of promise-keeping salient to both the person making the promise and the person receiving the promise. In our experimental agency setting, the activation of this social norm would lead to promise-keeping behavior in the agent and trusting behavior in the principal. Thus, our study contributes to the management accounting literature by demonstrating the effectiveness of the promise-keeping norm in a principal-agent setting and the ability of cheap talk on the part of the agent to activate this social norm. While researchers in economics have begun to examine benefits from cheap talk emanating from the agent (Brandts and Cooper 2007), researchers 
in management accounting have only examined benefits from cheap talk emanating from the principal (Kachelmeier et al. 1994; Rankin et al. 2003).

Our main result, that the agent's communication of a promised level of effort is effective at mitigating agency problems in the presence of a very noisy performance measure, should be good news to managers and policy makers. Organizational settings can frequently contain very noisy performance measures (Lambert 2001). Examples where the link between effort and performance is indirect or poorly understood include non-profit settings (Rose-Ackerman 1996), and settings where skill and creativity are a large component of output such as with accountants, lawyers, engineers, and academics (Kachelmeier et al. 2008; Stevens and Thevaranjan 2010). Given traditional agency assumptions, it would be very difficult to arrange an efficient incentive contract in such organizational settings. Noisy performance measures not only make traditional incentive solutions prohibitively expensive, they also make reputation-building over multiple periods very difficult as output provides limited information on effort. Thus, pre-contract communication of promised effort on the part of the agent may be an important part of organizational control that has not been previously recognized in the literature. Our results contribute to the extensive experimental literature in economics documenting that participants frequently exhibit "repeated play behavior" in single-period settings and achieve cooperative solutions that surpass game theoretic predictions based on narrow self-interest (Smith 2010). Our results also contribute to the experimental literature in management accounting examining alternative solutions to agency problems in the firm (Brown et al. 2009).

The remainder of this study is organized as follows. In the following section we present the theoretical foundation for our study and develop the hypotheses we test. We explain our experimental methodology in the third section and present our results in the fourth section. In the final section we present our conclusions.

\section{HYPOTHESIS DEVELOPMENT}

We develop the hypotheses we test using the principal-agent model in Stevens and Thevaranjan (2010) and in Bicchieri's (2006) model of social norm activation. In the traditional principal-agent model, the principal hires the agent to perform some productive effort on the principal's behalf. The principal is typically assumed to be risk-neutral, whereas the agent is assumed to be risk-averse and effort-averse. When there is information asymmetry regarding the agent's effort, as is typically assumed, a moral hazard arises in which the agent is expected to shirk and provide the minimal possible effort after contracting with the principal (Lambert 2001; Stevens and Thevaranjan 2010). Thus, the principal must induce the agent to provide effort by using an incentive contract that ties the agent's pay to some performance measure that captures the effort of the agent with noise. Because the agent is risk-averse, however, the principal must pay the agent a risk premium that is increasing in the noisiness of the performance measure. Thus, the traditional incentive solution is costly and becomes increasingly costly with increases in the noisiness of the performance measure (Lambert 2001). When the performance measure is very noisy, it may be uncontractable and the traditional incentive solution may be unavailable (Stevens and Thevaranjan 2010).

When the principal-agent relation is extended to multiple periods, the range of possible outcomes is greatly increased (Miller 1992). In particular, new solutions arise based on observable performance measures and reinforced expectations over time. Prior experimental studies in accounting and economics have found that repeat interaction increases the potential for cooperative behavior, leading to superior outcomes for the principal and the agent (Schatzberg and Stevens 2008; Fisher et al. 2008; Kuang and Moser 2009; Smith 2010). Further, agency theorists have long included the possibility of reputation building in multi-period settings (Baiman 1982, 1990; 
Lambert 2001). It is very difficult for the agent to build a reputation, however, in the presence of a very noisy performance measure that reveals very little information regarding the agent's effort. Yet, as we discuss in the introduction, there are many organizational settings where available performance measures are likely to be very noisy indicators of effort (Lambert 2001; Kachelmeier et al. 2008; Stevens and Thevaranjan 2010).

To help explain a wider range of contracting behavior within the firm, Stevens and Thevaranjan (2010) develop a single-period principal-agent model that incorporates a morally sensitive agent. In their model, the agent possesses some level of moral sensitivity that causes him disutility if he provides less than a previously agreed-upon level of effort. This disutility is a joint function of the moral sensitivity of the agent, and the difference between the agreed upon effort and actual effort. Stevens and Thevaranjan (2010) compare the "moral" solution that emerges when the moral sensitivity of the agent is nonzero with the traditional incentive solution that is required when moral sensitivity is assumed to be zero. Stevens and Thevaranjan (2010) find that a work ethic arises in their model that is a function of the agent's risk preference and moral sensitivity. Because of this work ethic, the agent is willing to provide up to a minimum ("fair") level of effort to the principal for a wage that pays the cost of that effort. To induce more than this minimum level of effort from the agent, however, the principal must pay the agent a "salary bonus" that effectively shares some of the resulting gain with the agent. Thus, the opportunity for gift exchange behavior arises in Stevens and Thevaranjan's (2010) model as a result of the moral sensitivity of the agent. This form of gift exchange, however, only arises when it is profitable for the principal to induce more than the minimum level of effort from the agent, which Stevens and Thevaranjan (2020) argue is consistent with the empirical evidence. ${ }^{1}$

Stevens and Thevaranjan (2010) attribute their disutility for providing less than a previously agreed-upon level of effort to the social norm of promise-keeping. They argue that the norm of promise-keeping spans culture and time and provides the foundation for all philosophical theories of ethics. Thus, their model expands traditional principal-agent theory by incorporating insights from moral philosophy and social norm theory. However, as is common among principal-agent models, Stevens and Thevaranjan (2010) assume that all information is common knowledge except the effort provided by the agent. Thus, the agent's moral sensitivity is known by the principal at the time of contracting. Stevens and Thevaranjan (2010) do not consider a setting where there is information asymmetry regarding the agent's moral or effort type at the time of contracting and, therefore, a potential gain from the communication of a promised level of effort. Further, they do not examine a multi-period setting where the agent can build a reputation over time. Finally, their model does not consider the possibility of environmental cues activating the social norm of promise-keeping in the agent and the principal.

Bicchieri (2006) provides a model of social norm activation that is based on experimental tests of game theory in economics. Until very recently, most experimental studies in economics have been designed to show that human behavior frequently deviates from the traditional assumption of narrow self-interest. Emerging results from these experiments suggest that other-regarding preferences and social norms are a major motivator of economic decision-making behavior (Smith 2010). These experimental studies, however, provide little insight regarding why actors appear to have other-regarding preferences. Bicchieri's (2006) model of social norm activation explains how

\footnotetext{
${ }^{1}$ A key result of Stevens and Thevaranjan's (2010) model is that the first-best solution is achievable when the firm has low productivity or the agent has high moral sensitivity. Under these special conditions, the principal can contract to pay the agent a flat salary that equals the agent's cost of providing the optimal level of effort for the firm. Stevens and Thevaranjan (2010) conclude that adding moral sensitivity increases the descriptive, prescriptive, and pedagogical usefulness of the principal-agent model. Mittendorf (2006) also incorporates agents that vary in their utility for honest reporting in his model of capital budgeting.
} 
people map contexts into specific interpretations that involve inferences about other people's motives and expectations of future behavior. The model suggests that the mapping from context to social norm activation goes through attention to cues, interpretation of cues (categorization), and scripts. Thus, social norm activation relies on past experiences and present perceptions that shape beliefs and expectations.

Bicchieri's (2006) model suggests that a social norm is activated and followed when individuals become aware of a behavioral rule that is relevant to the current situation, and the combination of empirical and normative expectations gives individuals a sufficient reason to follow the behavioral rule. The choice to follow a social norm is conditional upon one's beliefs about how many other people are going to follow it and whether one is expected to follow it in turn by a sufficient number of people. Bicchieri $(2006,148)$ argues that the very act of promising focuses subjects on a norm of promise-keeping and fosters expectations that a sufficient number of subjects will fulfill their promises. This is a powerful social norm because it relates closely to a person's identity and social experience. We usually keep our promises and we expect others to keep theirs. Thus, Bicchieri's (2006) model suggests that giving the agent the ability to communicate a promised level of effort prior to contracting will activate the social norm of promise-keeping in both the agent and the principal, thereby leading to promise-keeping behavior in the agent and trusting behavior in the principal.

Traditional agency theory, in contrast, would predict that the agent's communication of promised effort is only cheap talk that will have no effect on the effort provided by the agent or the pay offered by the principal. This prediction, however, is contradicted by robust experimental findings in both accounting and economics that cheap talk is "sticky" to both the recipients and senders of the unenforceable signal (Farrell 1987, 1993; Kachelmeier et al. 1994; Rankin et al. 2003; Brandts and Cooper 2007). In related experimental research in management accounting, participants have been found to be motivated by social norms for honesty, which is reflected in the fact that participants frequently provide "truthful" budgets in participative budgeting settings where the economic incentive is to build significant slack into their budgets (Evans et al. 2001; Stevens 2002; Hannan et al. 2006; Rankin et al. 2008; Hobson et al. 2011). Of particular relevance to this study, Rankin et al. (2008) find that having participants communicate their budget request in the form of a factual assertion reduces budgetary slack under a slack-inducing pay scheme. Consistent with Bicchieri's (2006) model, the factual assertion apparently activated the social norm of honesty in participants by linking budgetary slack to dishonest statements about expected production costs.

Given the principal-agent model in Stevens and Thevaranjan (2010), the model of social norm activation in Bicchieri (2006), and prior experimental results in management accounting, we expect the agent's communication of promised effort to activate the social norm of promise-keeping in the agent and the principal. Further, we expect the activation of this social norm to generate promise-keeping behavior in the agent and trusting behavior in the principal, thereby turning the agent's communication of promised effort into an effective signaling device that yields superior results for the agent. Our first hypothesis tests the effect of the agent's cheap talk on the agent's outcomes in a single-period setting where effort is unobservable and production is a very noisy measure of effort. We predict that the communication of promised effort by the agent will result in higher effort and higher pay in this setting. This prediction is stated formally below:

H1: In a single-period setting where effort is unobservable and production is a very noisy measure of effort, pre-contract communication of promised effort by the agent will result in higher effort and higher pay.

Our second hypothesis tests the effect of the agent's cheap talk on expected firm profit in a single-period setting, where effort is unobservable and production is a very noisy measure of effort. The promise-keeping norm has the potential to motivate gift exchange behavior between the 
principal and the agent that is profitable to the firm. The principal-agent model by Stevens and Thevaranjan (2010) suggests that the principal will only initiate gift-exchange behavior if it is profitable for the firm to induce more than a minimal level of effort, and the outcome of such gift exchange behavior is a sharing of the incremental profit with the agent. In our experimental agency setting, the knowledge that the agent's moral sensitivity makes the promised level of effort attainable enables the principal to choose a more profitable wage for the firm. Thus, the moral sensitivity of the agent allows the principal to profit from gift-exchange behavior. Based on the principal-agent model in Stevens and Thevaranjan (2010) and the model of social norm activation in Bicchieri (2006), therefore, we assert that the activation of the promise-keeping norm by the agent's communication of promised effort will induce gift exchange behavior that is profitable to the firm. Thus, we predict that the communication of promised effort by the agent will result in higher expected profit for the principal in our experimental setting. This prediction is stated formally below:

H2: In a single-period setting where effort is unobservable and production is a very noisy measure of effort, pre-contract communication of promised effort by the agent will result in higher expected profit for the principal.

When the principal-agent relation is extended to multi-periods, the range of possible outcomes is greatly increased (Miller 1992). In particular, new solutions arise based on past performance and reinforced expectations over time. Consistent with traditional agency theory and prior experimental evidence, we expect that repeat interaction with the same principal will motivate the agent to create a reputation for providing higher effort in order to generate higher wages from the principal in future periods. Such reputation building, however, is likely to be unsuccessful in a setting where the production outcome is a very noisy measure of effort. Thus, the communication of promised effort may continue to be an important and effective method of yielding superior results in multi-period settings where available performance measures are very noisy. An important aspect of Bicchieri's (2006) model of social norm activation is the notion of Bayesian updating of expectations over multiple periods. If the empirical and normative expectation conditions of the model are fulfilled, the principal will assess a higher probability that she will be matched with an agent who keeps his promises. The principal is expected to revise her probabilistic assessment downward, however, if observed behavior suggests that this is not the case. Thus, disconfirming evidence will lead to a decay in promise-keeping expectations and behavior over time, consistent with many experimental tests of cooperative behavior in two-person games (Bicchieri 2006; Smith 2010). This raises an interesting research question regarding the ability of agent cheap talk to yield superior outcomes for the agent and the principal in a multi-period setting where effort is unobservable and production is a very noisy measure of effort. This research question is stated formally below:

RQ: In a multi-period setting where effort is unobservable and production is a very noisy measure of effort, will pre-contract communication of promised effort by the agent yield superior outcomes for the agent and the principal?

\section{METHODOLOGY}

We test our two hypotheses and address our research question using controlled laboratory experiments conducted on the campus of a large Midwestern university in the United States. Participants in the study included 120 students, of which 92 percent were undergraduates. The experiment was programmed in z-Tree (Fischbacher 2007) and was conducted on computer terminals over 13 experimental sessions, with 6-14 participants per session. At the beginning of each session, the instructions explained how roles were assigned, how production outcomes were 
determined, and how workers' earnings were calculated. The instructions specifically revealed that managers' earnings were a function of worker production and the worker's wage. Participants were then randomly assigned to the role of manager or worker, which they retained throughout the entire session. At this point, managers were informed that they would also receive a bonus for accurately forecasting employee effort each period. Knowledge of the forecast bonus was withheld from workers to disable relative pay comparisons and reduce the likelihood of strategic behavior based on "even split" or fairness motivations (Stevens and Thevaranjan 2010; Smith 2010).

Each period, the manager offered the worker a wage in exchange for production effort. The worker could choose one of three production effort levels: low, medium, or high. If the worker declined the wage offer, both the worker and the manager earned an amount representing their outside opportunity cost. In particular, the worker and manager both earned \$2.00 if no contracting took place in a given production period. The experiment continued until at least 10 periods were completed. After 10 periods, there was a 50 percent chance that the experiment would end before the next period. Seven sessions ended after 10 periods, 2 sessions ended after 11 periods, 3 sessions ended after 12 periods, and one session ended after 14 periods. The procedure that determined the final period was common knowledge; it was used to prevent "end-of-game" behavior. ${ }^{2}$

The parameters used in the experiment assured that participants faced the traditional agency problem. The worker's pay function reflected the traditional convex cost of effort and assured that the worker was always motivated to provide low effort. In particular, the worker's pay function for each production period was:

\section{Worker Pay $=$ Worker Wage - Effort Charge}

where the worker wage ranged from $\$ 0.00$ to $\$ 6.00$ and the effort charge $=\$ 0.50, \$ 1.00$, and $\$ 2.00$ for low, medium, and high production effort, respectively.

The manager's pay function assured that the manager was always motivated to induce high effort with the lowest wage possible and to accurately predict the effort provided by the worker. In particular, the manager's pay function for each period was:

\section{Manager Pay $=(\$ 1.00 \times$ Production Output $)-$ Worker Wage + Forecast Bonus}

where the production output could be either 4 or 12 units, with the probability of the higher production output increasing from 0.25 to 0.50 to 0.75 as the effort level went from low to medium to high, respectively. Thus, expected output increased from 6 to 8 to 10 as the effort level went from low to medium to high. The choice of only two levels of production output with a reasonable chance of either output being realized under all three effort levels was intended to create an environment where the relationship of effort to production output was very noisy. The forecast bonus was determined as follows. After the wage offer was accepted but before production was revealed, the manager distributed 10 chips among three buckets, one for each effort level. The manager received $\$ 0.10$ for each chip placed in the correct bucket. All information was common knowledge except the effort provided by the agent and the forecast bonus of the manager. To keep the manager from learning the actual effort provided by the worker in any given production period, the forecast bonus was disclosed and paid to managers in total at the end of the experiment.

The experiment included two independent variables manipulated at two levels each to form a 2 $\times 2$ factorial design. We manipulated the absence or presence of cheap talk and whether the manager-worker relation was single-period or multi-period. In the "no cheap talk/single-period" control condition, the worker could not communicate his promised effort and interacted with a

\footnotetext{
2 A stochastically determined endpoint is commonly used in experimental economics studies to approximate an infinite time horizon and minimize backward-induction solutions (Schatzberg and Stevens 2008).
} 
different manager each period. In the "cheap talk/single-period" condition, the worker still interacted with a different manager each period but could communicate his promised effort to the manager prior to contracting. This communication was cheap talk because the manager knew that the worker could provide any level of effort after contracting with the manager. In the "no cheap talk/multi-period" condition, the worker could not communicate his promised effort to the manager prior to contracting, but interacted with the same manager across all periods. Finally, we completed our $2 \times 2$ factorial design by including a "cheap talk/multi-period" condition, where the worker could communicate his promised effort to the manager prior to contracting, and interacted with the same manager across all periods.

All participants received their earnings in private at the end of the experiment after completing an exit questionnaire. ${ }^{3}$ Earnings were paid out in cash using a deflation factor of 2.5 , which was explained at the beginning of the experiment. The average compensation per participant was $\$ 31.01$ for the approximately two hours it took to complete the experiment.

\section{RESULTS}

Exit questionnaire answers reveal that 70 of the 120 students who participated in the experiment were female and 50 were male. Participants were mostly undergraduate students (92 percent) who were accounting majors (68 percent). Some statements in the exit questionnaire tested the effectiveness of our two experimental manipulations. Participants responded to these statements on a Likert scale from 1-Strongly Disagree to 7-Strongly Agree, with 4 being Neutral. All manipulation tests are tests of the mean response from the neutral response of 4 . The 60 participants under the two cheap talk conditions correctly agreed that the worker signaled promised effort prior to receiving a wage offer from the manager (mean $=5.93: \mathrm{p}<0.01$ ) whereas the other 60 participants correctly disagreed with that statement (mean $=2.27 ; \mathrm{p}<0.01)$. The 60 participants under the two cheap talk conditions also correctly agreed that the worker could provide any level of effort after contracting with the manager (mean $=6.35 ; \mathrm{p}<0.01$ ). Finally, the 60 participants under the two single-period conditions correctly agreed that the worker interacted with a different manager each period (mean $=5.12 ; \mathrm{p}<0.01$ ), whereas the 60 participants under the two multi-period conditions correctly disagreed with that statement (mean $=2.50 ; \mathrm{p}<0.01$ ). These results suggest that our two experimental manipulations were fully successful.

Figure 1 presents average wage offers by experimental group across periods $1-10 .{ }^{4}$ This figure suggests that the two cheap talk conditions yielded higher wage offers on average than the other two conditions where cheap talk was absent. Figure 2 presents average production effort by experimental group across periods 1-10. For this figure and future statistical tests on effort, low effort is coded as 1 , medium effort is coded as 2 , and high effort is coded as 3 . Figure 2 suggests that the two cheap talk conditions yielded higher effort on average than the other two conditions where cheap talk was absent. Figure 3 presents average expected firm profit by experimental group across periods 1-10. We utilize expected firm profit instead of actual firm profit as this allows us to remove the noise caused by the random draw of realized production output from our dependent variable. This is consistent with previous experimental research that uses probabilistic outcomes

\footnotetext{
3 The exit questionnaire gathered demographic information, manipulation checks, and measures of participant perceptions. Participants also completed the Jackson Personality Inventory-Revised (Jackson 1994) online before arriving at the experimental lab. We do not report results from this personality test, as personality factors are not the focus of this study.

4 Figures, descriptive statistics, and hypothesis tests include only periods $1-10$ because this is the standard number of periods experienced by all experimental groups. As described above, the number of periods experienced by each group varied from 10 to 14 due to the random ending point. As a sensitivity analysis, we also conducted hypothesis tests using all observed data; results are qualitatively unchanged.
} 


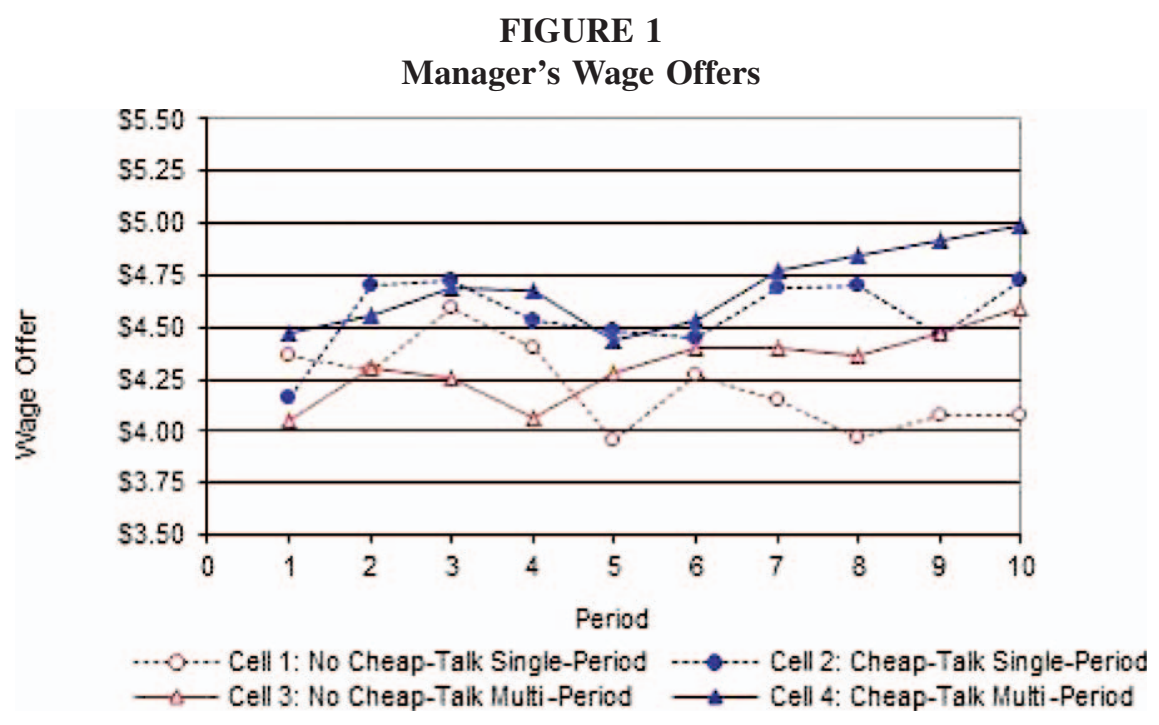

(e.g., Evans et al. 2001). Expected firm profit is calculated as expected production output for the effort level provided $(6,8$, or 10 for low, medium, or high, respectively) less the actual wage paid. Figure 3 suggests that the two cheap talk conditions yielded higher expected profit on average than the other two conditions where cheap talk was absent. To provide a more detailed presentation of wage and effort behavior, Figure 4 presents histograms of accepted wages by experimental group and Figure 5 presents histograms of effort provided by experimental group. These histograms provide further evidence that wages and effort were higher on average under the two cheap talk conditions.

Table 1 presents descriptive statistics by the four cells of our experimental design. Given traditional agency theory assumptions and unobservable effort in a single-period setting, the agent

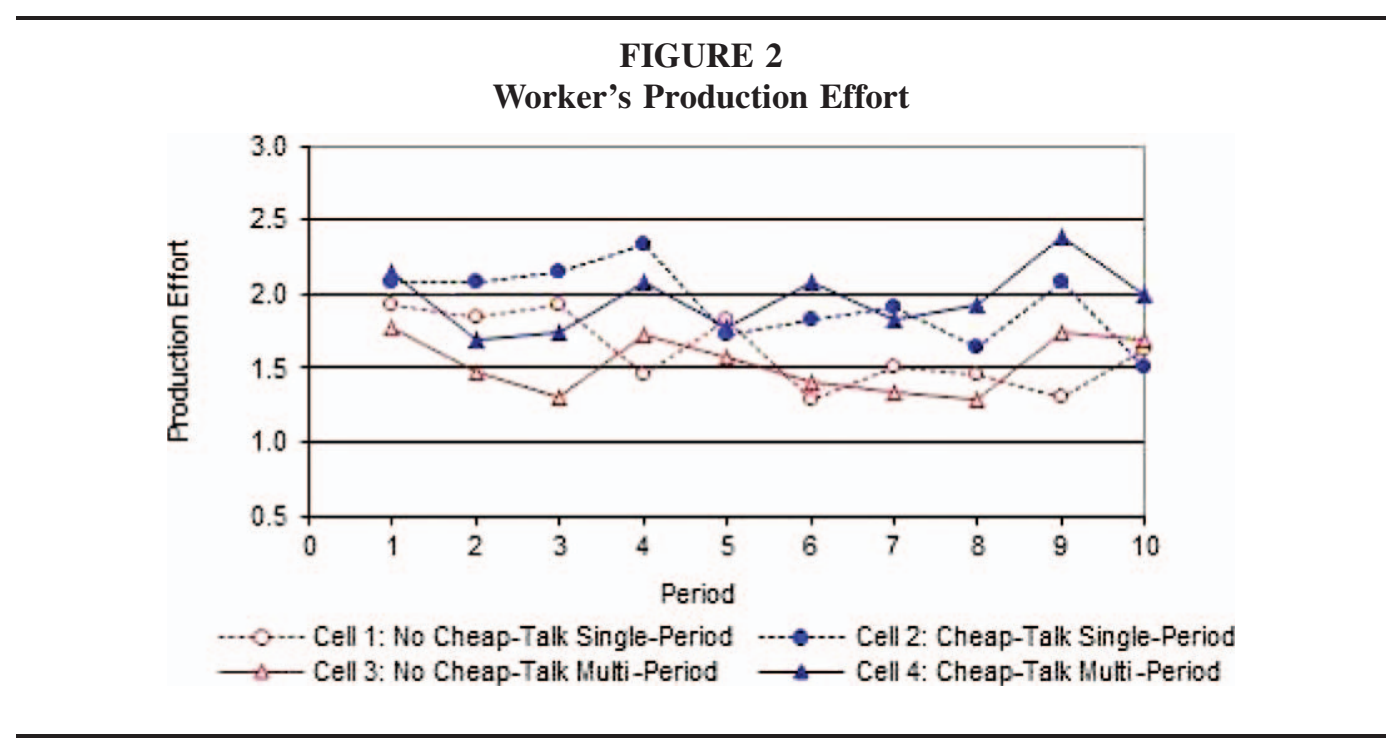




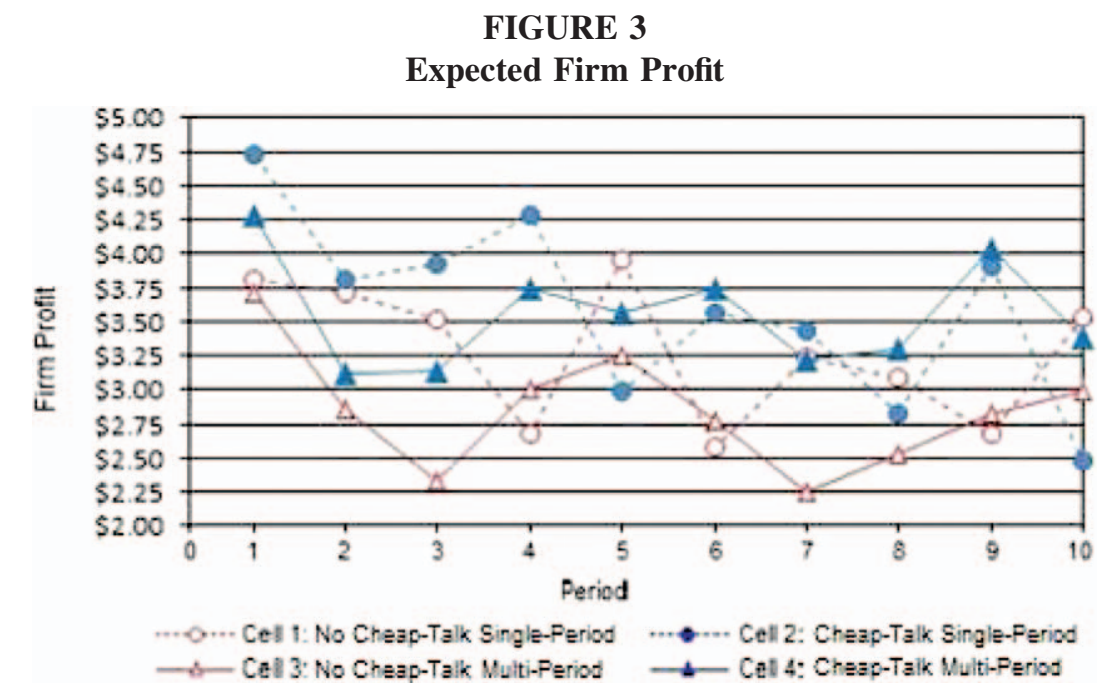

is expected to receive low pay from the principal in exchange for low effort. In particular, the agent is expected to receive from the principal the agent's outside opportunity cost plus the cost for low effort, because the principal knows that the agent is effort-averse and is thereby motivated to only provide low effort (Stevens and Thevaranjan 2010). In our experimental setting, the outside opportunity cost and the cost of low effort formed a lower bound for pay of $\$ 2.50$ ( $\$ 2.00$ opportunity cost and $\$ 0.50$ cost of low effort). The statistics in Table 1 reveal that all experimental groups avoided the inferior outcome predicted by traditional agency theory. In all four cells, average effort levels are significantly above the low level (coded as 1), and average wages (both offered and accepted) are significantly above the $\$ 2.50$ minimum (all with $\mathrm{p}<0.01$ ). The "no cheap talk/single-period" control group in Cell 1 provided the ex ante greatest likelihood of realizing the agency theory prediction. Without the availability of communicating promised effort or building a reputation over multiple periods, the workers in the control group still received wage offers of $\$ 4.22$, accepted wage offers of $\$ 4.35$ on average, and provided average production effort of 1.61. These results reflect a gift exchange between the manager and worker (Akerlof 1982), consistent with prior experimental studies in accounting and economics (e.g., Hannan et al. 2002; Hannan 2005; Brandts and Cooper 2006, 2007; Kuang and Moser 2009).

Surprisingly, the mean forecast error is the largest for the "no cheap talk/multi-period" condition (0.48), followed by the "no cheap talk/single-period" condition (0.42), the "cheap talk/ multi-period" condition (0.33), and the "cheap talk/single-period" condition (0.28), although not all of these differences are statistically significant. The forecast error for the "no cheap talk/ multi-period" condition is significantly higher than the "cheap talk/single-period" and "cheap talk/ multi-period" conditions ( $\mathrm{p}=0.04$ and $\mathrm{p}=0.09$, respectively). Further, the forecast error for the "no cheap talk/single-period" condition is marginally higher than the "cheap talk/single-period" condition $(\mathrm{p}=0.11)$. These forecast error results suggest two things. First, the high mean forecast error in the "no cheap talk/multi-period" condition provides evidence that production was a very noisy measure of effort in our experiment, causing reputation formation to be ineffective. Second, the low mean forecast error in the "cheap talk/single-period" condition suggests that the communication of promised effort generated more accurate expectations of worker effort in the managers. Thus, managers were able to rely on the communication of promised effort by workers in 
FIGURE 4

Accepted Wages by Treatment

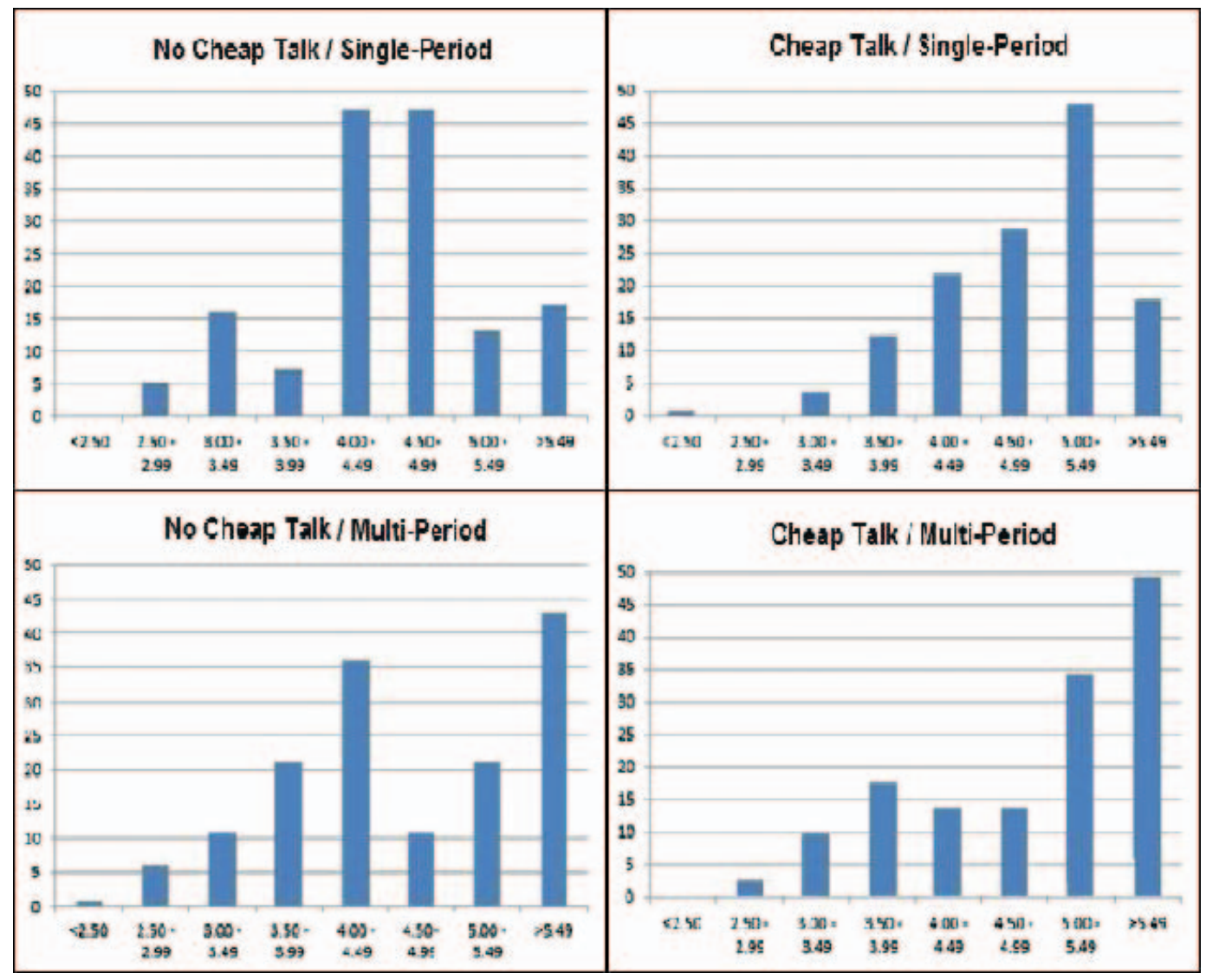

this noisy environment. Because of the way managers were compensated for accurate forecasts ( $\$ 0.10$ for each of the 10 chips placed in the correct effort bucket), however, the forecast bonus earned by managers is not significantly different across the four experimental groups. ${ }^{5}$

To provide direct evidence regarding the effectiveness of our noisy performance measure at prohibiting reputation formation as an agency solution, we examine expected firm profit across the two no cheap talk conditions that varied only in that they used either single-period or multi-period settings. In untabulated results of a repeated measures ANOVA, we find an insignificant effect of allowing managers to interact with the same worker throughout the experiment $(F=1.266, p=0.27)$. This result, combined with the result in Table 1 that the lowest expected firm profit across the four experimental conditions was in the "no cheap talk/multi-period" condition, provides confirming

5 In untabled results, the mean forecast bonus per period is $\$ 0.36$ across all four experimental groups. The mean forecast bonus per period is $\$ 0.39$ for the "no cheap talk/single-period" group, $\$ 0.37$ for the "cheap talk/singleperiod" group, $\$ 0.33$ for the "no cheap talk/multi-period" group, and $\$ 0.36$ for the "cheap talk/multi-period" group. These means are not significantly different, and our results are qualitatively the same when firm profit includes the forecast bonus in addition to expected production profit. 


\section{FIGURE 5 \\ Effort Provided by Treatment \\ $($ Low $=1$, Medium $=2$, High $=3)$}

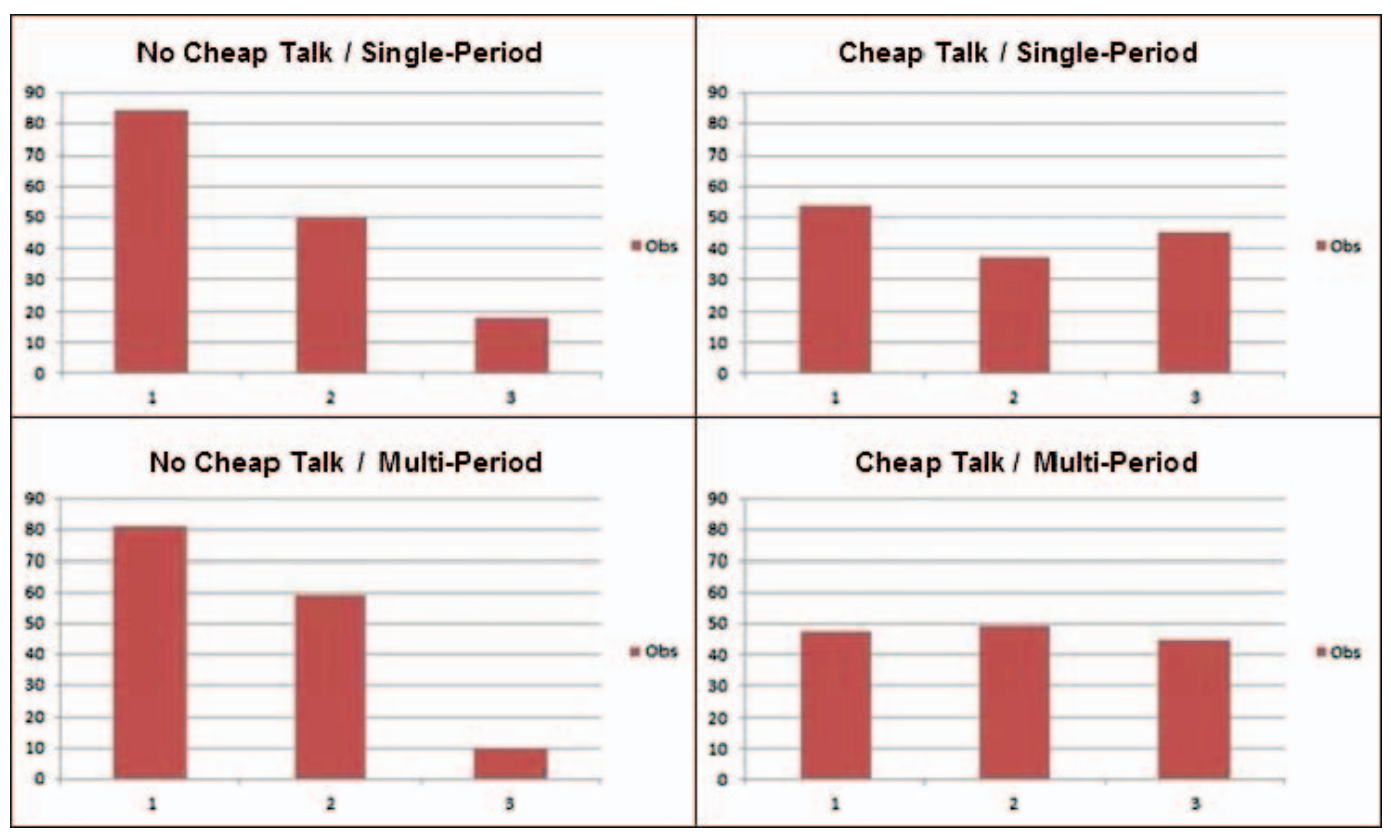

evidence that our production outcome was a sufficiently noisy measure of effort to make reputation-based agency solutions ineffective.

Table 2 presents the results of our hypothesis test for $\mathrm{H} 1$, which predicts that in a single-period setting, pre-contract communication of promised effort by the agent will result in higher effort and higher pay. To provide evidence regarding this hypothesis, we estimate a repeated measures MANOVA on our full model where the dependent variables are effort and accepted wages, the between-subject independent variables are the availability of cheap talk, the length of the manager/ worker relation, and the interaction of these factors, and the within-subject independent variable is period. We use a repeated measures analysis to control for multiple observations from each subject. The results of the repeated measures MANOVA estimated on the full model are presented in Panel A of Table 2. We find no significant within-subject effect of Period, and no significant interaction between Period and any of our between-subject factors for either dependent variable. We find a statistically significant effect of cheap talk on both effort and wages $(F=9.64, p<0.01 ; F=20.52$, $\mathrm{p}<0.01$, respectively), but no effect on wages or effort from increasing the length of the manager/ worker relation from single period to multi-period $(\mathrm{p}=0.89$ and $\mathrm{p}=0.15$, respectively). Additionally, we find no significant interactive effect of our two manipulations on effort or wage ( $\mathrm{p}$ $=0.24$ and $\mathrm{p}=0.90$, respectively).

In order to provide direct evidence regarding our H1, we test for the simple main effect of our cheap talk manipulation across the two single-period settings. In particular, we follow up the full model MANOVA with a repeated measurers MANOVA in our single-period conditions, where the dependent variables are effort and accepted wages, the between-subject independent variable is cheap talk, and the within-subject independent variable is period. The results of this analysis are presented in Panel B of Table 2. We find no significant within-subject effect of Period, and no 


\begin{tabular}{|c|c|c|c|c|c|c|c|}
\hline & Descriptive & tistics & $\begin{array}{l}\text { LE } 1 \\
\text { Experim }\end{array}$ & tal Co & lition & & \\
\hline & & & p Talk Ab & & & ap Talk Pre & \\
\hline & Variable & Mean & Std. Dev. & Obs. & Mean & Std. Dev. & Obs. \\
\hline & & & I 1 (Contr & & & Cell 2 & \\
\hline Single-Period & Offered Wages & 4.22 & 0.88 & 150 & 4.56 & 0.77 & 150 \\
\hline & Accepted Wages & 4.35 & 0.80 & 133 & 4.70 & 0.70 & 127 \\
\hline & Production Effort & 1.61 & 0.71 & 133 & 1.96 & 0.86 & 127 \\
\hline & Expected Firm Profit & 2.88 & 1.33 & 133 & 3.22 & 1.75 & 127 \\
\hline & Mean forecast error & 0.42 & 0.80 & 133 & 0.28 & 0.94 & 127 \\
\hline & & & Cell 3 & & & Cell 4 & \\
\hline Multi-Period & Offered Wages & 4.32 & 1.09 & 150 & 4.69 & 1.04 & 150 \\
\hline & Accepted Wages & 4.52 & 0.98 & 132 & 4.84 & 0.94 & 131 \\
\hline & Production Effort & 1.52 & 0.61 & 132 & 2.02 & 0.80 & 131 \\
\hline & Expected Firm Profit & 2.52 & 1.33 & 132 & 3.20 & 1.71 & 131 \\
\hline & Mean forecast error & 0.48 & 0.72 & 132 & 0.33 & 0.87 & 131 \\
\hline
\end{tabular}

significant interaction between Period and the cheap talk manipulation. Furthermore, as in the full model, we find that the presence of cheap talk led to higher effort $(F=4.16, p=0.04)$ and higher wages $(\mathrm{F}=13.14, \mathrm{p}<0.01)$. These findings remain significant when the F-statistics are converted to t-statistics to test our directional predictions. In particular, this analysis confirms that allowing cheap talk led to higher effort $(\mathrm{t}=2.04, \mathrm{p}=0.025)$ and higher wages $(\mathrm{t}=3.62, \mathrm{p}<0.01)$. These results collectively provide strong support for $\mathrm{H} 1$.

Table 3 presents the results of our hypothesis tests for $\mathrm{H} 2$, which predicts that in a single-period setting, pre-contract communication of promised effort by the agent will result in higher expected profit for the principal. To provide initial evidence regarding this hypothesis, we estimate a repeated measures ANOVA of the main effects and interactive effect of our manipulations on expected firm profit. The results of the repeated measures ANOVA on our full model are presented in Panel A of Table 3. We find a significant effect of Period $(\mathrm{F}=2.72, \mathrm{p}<0.01)$, but no significant interactive effects of Period and our between-subject factors ( $\mathrm{p}>0.10$ for all cases). ${ }^{6}$ As predicted, we find a significant main effect for cheap talk on expected firm profit $(\mathrm{F}=6.08, \mathrm{p}=0.02)$. We do not find evidence of a main effect of increasing the length of the manager/worker relation from single-period to multi-period or an interactive effect of our two manipulations ( $\mathrm{p}=0.47$ and 0.60 , respectively).

To examine the simple main effect of pre-contract communication of promised effort on expected firm profit in a single-period setting, we also conduct a repeated measures ANOVA of cheap talk on expected firm profit across the two single-period conditions. The results of this analysis are presented in Panel B of Table 3. We find a significant simple main effect of cheap talk on expected firm profit at the 10 percent level using a two-tailed F-test $(\mathrm{F}=3.21, \mathrm{p}=0.08)$. In order to test our directional prediction, we convert the F-statistic to a t-statistic so we can make directional inferences. This strengthens our finding, rejecting the null hypothesis of no effect of pre-contract ${ }^{6}$ Our results are qualitatively unchanged if period is cut into early period and late period and the analysis is run on
each half. 


\section{TABLE 2}

Effect of Cheap Talk on Effort and Pay in a Single-Period Setting (H1)

Panel A: Repeated Measures Multivariate Analysis of Variance-Full Model

\begin{tabular}{|c|c|c|c|c|}
\hline Factor & df & Sum of Squares & $\mathbf{F}$ & $\begin{array}{c}\text { p-value } \\
\text { (two-tailed) }\end{array}$ \\
\hline \multicolumn{5}{|l|}{ Dependent Variable_Effort } \\
\hline \multicolumn{5}{|l|}{ Between-subjects } \\
\hline Cheap Talk & 1 & 13.500 & 9.640 & 0.002 \\
\hline Multi-Period & 1 & 0.027 & 0.019 & 0.890 \\
\hline Cheap Talk $\times$ Multi-Period & 1 & 1.927 & 1.376 & 0.241 \\
\hline Error & 56 & & & \\
\hline \multicolumn{5}{|l|}{ Within-subjects } \\
\hline Period & 9 & 7.427 & 0.589 & 0.806 \\
\hline Period $\times$ Cheap Talk & 9 & 8.233 & 0.653 & 0.751 \\
\hline Period $\times$ Multi-Period & 9 & 16.507 & 1.310 & 0.229 \\
\hline Period $\times$ Cheap Talk $\times$ Multi-Period & 9 & 2.273 & 0.180 & 0.996 \\
\hline Error & 505 & & & \\
\hline \multicolumn{5}{|l|}{ Dependent Variable—Wage } \\
\hline \multicolumn{5}{|l|}{ Between-subjects } \\
\hline Cheap Talk & 1 & 19.124 & 20.518 & 0.000 \\
\hline Multi-Period & 1 & 1.936 & 2.077 & 0.150 \\
\hline Cheap Talk $\times$ Multi-Period & 1 & 0.016 & 0.017 & 0.896 \\
\hline Error & 56 & & & \\
\hline \multicolumn{5}{|l|}{ Within-subjects } \\
\hline Period & 9 & 6.140 & 0.732 & 0.680 \\
\hline Period $\times$ Cheap Talk & 9 & 3.265 & 0.389 & 0.940 \\
\hline Period $\times$ Multi-Period & 9 & 5.663 & 0.675 & 0.732 \\
\hline Period $\times$ Cheap Talk $\times$ Multi-Period & 9 & 3.841 & 0.458 & 0.903 \\
\hline Error & 505 & & & \\
\hline
\end{tabular}

Panel B: Repeated Measures Multivariate Analysis of Variance-Simple Effect of Communication in a Single-Period Setting

\begin{tabular}{|c|c|c|c|c|}
\hline Factor & df & Sum of Squares & $\mathbf{F}$ & $\begin{array}{c}\text { p-value } \\
\text { (two-tailed) }\end{array}$ \\
\hline \multicolumn{5}{|c|}{ Dependent Variable_Effort } \\
\hline \multicolumn{5}{|l|}{ Between-subjects } \\
\hline Cheap Talk & 1 & 3.853 & 4.160 & 0.042 \\
\hline Error & 28 & & & \\
\hline \multicolumn{5}{|l|}{ Within-subjects } \\
\hline Period & 9 & 11.280 & 1.353 & 0.209 \\
\hline Period $\times$ Cheap Talk & 9 & 3.880 & 0.465 & 0.897 \\
\hline Error & 252 & & & \\
\hline \multicolumn{5}{|c|}{ Dependent Variable_-Wage } \\
\hline \multicolumn{5}{|l|}{ Between-subjects } \\
\hline Cheap Talk & 1 & 9.020 & 13.138 & 0.000 \\
\hline Error & 28 & & & \\
\hline
\end{tabular}


TABLE 2 (continued)

\begin{tabular}{|c|c|c|c|c|}
\hline Factor & df & Sum of Squares & $\mathbf{F}$ & $\begin{array}{c}\text { p-value } \\
\text { (two-tailed) }\end{array}$ \\
\hline \multicolumn{5}{|l|}{ Within-subjects } \\
\hline Period & 9 & 4.561 & 0.738 & 0.674 \\
\hline Period $\times$ Cheap Talk & 9 & 5.548 & 0.898 & 0.528 \\
\hline Error & 252 & & & \\
\hline
\end{tabular}

communication of promised effort on expected firm profit at the 5 percent level $(t=1.79, p=0.04)$. These results collectively provide support for $\mathrm{H} 2$.

Our research question asks if in a multi-period setting, pre-contract communication of promised effort by the agent yields superior outcomes for the agent and the principal. To analyze this research question, we estimate a repeated measures MANOVA on the effect of cheap talk on effort, wages, and expected firm profit in the two multi-period conditions in order to test for the simple main effect of our cheap talk manipulation in a multi-period setting. The results from this

\section{TABLE 3}

Effect of Cheap Talk on Expected Firm Profit in a Single-Period Setting (H2)

Panel A: Repeated Measures Analysis of Variance-Full Model

\begin{tabular}{|c|c|c|c|c|}
\hline Factor & df & Sum of Squares & $\mathbf{F}$ & $\begin{array}{c}\text { p-value } \\
\text { (two-tailed) }\end{array}$ \\
\hline \multicolumn{5}{|l|}{ Between-subjects } \\
\hline Cheap Talk & 1 & 41.444 & 6.076 & 0.017 \\
\hline Multi-Period & 1 & 3.571 & 0.524 & 0.472 \\
\hline Cheap Talk $\times$ Multi-Period & 1 & 1.863 & 0.273 & 0.603 \\
\hline Error & 56 & & & \\
\hline \multicolumn{5}{|l|}{ Within-subjects } \\
\hline Period & 9 & 38.474 & 2.721 & 0.004 \\
\hline Period $\times$ Cheap Talk & 9 & 20.631 & 1.459 & 0.160 \\
\hline Period $\times$ Multi-Period & 9 & 18.295 & 1.294 & 0.237 \\
\hline Period $\times$ Cheap Talk $\times$ Multi-Period & 9 & 10.391 & 0.735 & 0.677 \\
\hline Error & 504 & & & \\
\hline
\end{tabular}

Panel B: Repeated Measures Analysis of Variance-Simple Effect of Cheap Talk in the Single-Period Setting

\begin{tabular}{|c|c|c|c|c|}
\hline Factor & df & Sum of Squares & $\mathbf{F}$ & $\begin{array}{c}\text { p-value } \\
\text { (two-tailed) }\end{array}$ \\
\hline \multicolumn{5}{|l|}{ Between-subjects } \\
\hline Cheap Talk & 1 & 12.867 & 3.208 & 0.084 \\
\hline Error & 28 & & & \\
\hline \multicolumn{5}{|l|}{ Within-subjects } \\
\hline Period & 9 & 29.560 & 1.721 & 0.085 \\
\hline Period $\times$ Cheap Talk & 9 & 24.558 & 1.430 & 0.176 \\
\hline Error & 252 & & & \\
\hline
\end{tabular}


analysis are presented in Table 4. We find a significant effect for cheap talk in a multi-period setting on effort $(\mathrm{F}=9.74, \mathrm{p}<0.01)$, wages $(\mathrm{F}=8.59, \mathrm{p}<0.01)$, and expected firm profit $(\mathrm{F}=3.16, \mathrm{p}=$ 0.086). This is consistent with the results found in the single-period setting. Thus, we find evidence that the pre-contract communication of promised effort continues to generate higher effort, wages, and expected firm profit in a multi-period setting. Thus, our research question is answered in the affirmative.

To provide a more detailed analysis of our cheap talk results, we present a series of ordered probit regressions on effort. While half of our data form a repeated single-period setting because of the rotation of managers and workers each period, the other half form a multi-period setting where managers and workers remain paired together throughout the entire experiment. Because of this lack of independence and the repeated observations from each participant, we use ordered probit regressions with clustered error terms. In particular, all of our regression analyses cluster on subject-level error terms to control for the repeated measure nature of our observations. Our first ordered probit regression provides a detailed analysis of the effort results in all four experimental

\section{TABLE 4}

Effect of Cheap Talk on Effort, Wages, and Expected Firm Profit in a Multi-Period Setting (Research Question)

Repeated Measures Multivariate Analysis of Variance-Simple Effect of Cheap Talk in the Multi-Period Setting

\begin{tabular}{|c|c|c|c|c|}
\hline Factor & df & Sum of Squares & $\mathbf{F}$ & $\begin{array}{c}\text { p-value } \\
\text { (two-tailed) }\end{array}$ \\
\hline \multicolumn{5}{|l|}{ Dependent Variable_Effort } \\
\hline \multicolumn{5}{|l|}{ Between-subjects } \\
\hline Cheap Talk & 1 & 12.813 & 9.735 & 0.002 \\
\hline Error & 28 & & & \\
\hline \multicolumn{5}{|l|}{ Within-subjects } \\
\hline Period & 9 & 9.253 & 0.781 & 0.634 \\
\hline Period $\times$ Cheap Talk & 9 & 6.787 & 0.573 & 0.819 \\
\hline Error & 252 & & & \\
\hline \multicolumn{5}{|l|}{ Dependent Variable—Wage } \\
\hline \multicolumn{5}{|c|}{ Between-subjects } \\
\hline Cheap Talk & 1 & 10.120 & 8.594 & 0.004 \\
\hline Error & 28 & & & \\
\hline \multicolumn{5}{|l|}{ Within-subjects } \\
\hline Period & 9 & 7.242 & 0.683 & 0.724 \\
\hline Period $\times$ Cheap Talk & 9 & 1.558 & 0.147 & 0.998 \\
\hline Error & 252 & & & \\
\hline \multicolumn{5}{|c|}{ Dependent Variable_Expected Firm Profit } \\
\hline \multicolumn{5}{|c|}{ Between-subjects } \\
\hline Cheap Talk & 1 & 30.439 & 3.161 & 0.086 \\
\hline Error & 28 & & & \\
\hline \multicolumn{5}{|l|}{ Within-subjects } \\
\hline Period & 9 & 27.209 & 2.451 & 0.011 \\
\hline Period $\times$ Cheap Talk & 9 & 6.464 & 0.582 & 0.811 \\
\hline Error & 252 & & & \\
\hline
\end{tabular}


cells while controlling for gift exchange behavior. In Model 1 we regress the effort provided in all four cells on the Cheap Talk and Multi-Period manipulations, their interaction (Cheap Talk $\times$ Multi-Period), and two accepted wage variables (Wage and $\Delta$ Wage), while controlling for the level of effort in the previous period (Previous Effort). ${ }^{7}$

\section{Model 1:}

$$
\begin{aligned}
\text { Effort }= & \beta_{1} \text { Cheap Talk }+\beta_{2} \text { Multi-Period }+\beta_{3} \text { Cheap Talk } \times \text { Multi-Period }+\beta_{4} \text { Wage } \\
& +\beta_{5} \Delta \text { Wage }+\beta_{6} \text { Previous Effort },
\end{aligned}
$$

where Effort is the effort provided by an employee in a given period, coded as 1, 2, and 3 for low, medium, and high; Cheap Talk is a dummy variable equal to 1 if pre-contract communication of promised effort is present, and 0 otherwise; Multi-Period is a dummy variable equal to 1 if the worker and manager are paired for the entire experiment, and 0 otherwise; Cheap Talk $\times$ MultiPeriod is the interaction of Cheap Talk and Multi-Period; Wage is the wage paid to the worker in a given period; $\Delta W a g e$ is (Wage - Prior Period's Wage)/Prior Period's Wage; and Previous Effort is the effort provided in the prior period.

The results of Model 1 are presented in Table 5. The coefficient on Cheap Talk $\left(\beta_{1}\right)$ is highly significant $(\mathrm{p}<0.01)$ and positive, whereas the coefficients on Multi-Period $\left(\beta_{2}\right)$ and Cheap Talk $\times$ Multi-Period $\left(\beta_{3}\right)$ are not significant. Consistent with a gift exchange, the coefficients on both Wage and $\Delta$ Wage $\left(\beta_{3}\right.$ and $\beta_{4}$, respectively) are highly significant $(\mathrm{p}<$ 0.01 ) and positive. These results support our previous findings regarding H1 by demonstrating that the cheap talk manipulation resulted in higher worker effort after controlling for the effects of gift exchange.

To provide further insights regarding our cheap talk results, we next use the ordered probit regression in Equation (2) on data from the two cheap talk conditions to examine if the promised effort communicated by the worker affected actual effort provided by the worker.

\section{Model 2:}

Effort $=\beta_{1}$ Wage $+\beta_{2} \Delta$ Wage $+\beta_{3}$ Promise $+\beta_{4}$ Period $+\beta_{5}$ Late Period $+\beta_{6}$ Previous Effort,

where Promise is the promised level of effort; Period is the period of the experiment (1-10); Late Period is a dummy variable that is 1 when the period is greater than period seven, and 0 otherwise; and all other variables are defined as in Equation (1).

The results of Model 2 are presented in Table 6 . With all variables in the model, the coefficient on Promise $\left(\beta_{3}\right)$ is significant $(\mathrm{p}<0.01)$ and positive. This confirms that workers who communicated higher promised levels of effort tended to provide higher actual levels of effort, following the promise-keeping norm, even though their promised effort level was unenforceable and therefore only cheap talk. Furthermore, this supports that workers had an incremental concern for promise-keeping above and beyond their utility for maintaining a gift exchange relationship. Gift exchange still influences behavior in the cheap talk setting, however, as the coefficients on Wage $\left(\beta_{1}\right)$ and $\Delta$ Wage $\left(\beta_{2}\right)$ are highly significant $(\mathrm{p}<0.01)$ and positive. None of the period-related coefficients in the model reach significance. ${ }^{8}$

Given our finding that workers tend to follow through on their promised level of effort, we further investigate the motivation for this tendency by examining the deviation from the promised effort using the probit model in Equation (3) on the two cheap talk conditions.

\footnotetext{
7 We include the Previous Effort variable to control for a natural inclination to maintain an effort level. Excluding Previous Effort, however, does not qualitatively change the results of the model.

${ }^{8}$ Excluding Previous Effort does not qualitatively change the results of the model.
} 


\section{TABLE 5}

\section{Results of Ordered Probit Regressions of Effort in All Experimental Conditions (with Clustered Error Terms)}

\begin{tabular}{|c|c|}
\hline & Model 1 \\
\hline Cheap Talk & $\begin{array}{l}0.656 \\
(2.75)^{* * * *}\end{array}$ \\
\hline Multi-Period & $\begin{array}{l}-0.200 \\
(-1.11)\end{array}$ \\
\hline Cheap Talk $\times$ Multi-Period & $\begin{array}{c}0.238 \\
(0.80)\end{array}$ \\
\hline Wage & $\begin{array}{l}0.233 \\
(2.65)^{* * * *}\end{array}$ \\
\hline$\Delta$ Wage & $\begin{array}{l}0.206 \\
(7.85)^{* * * *}\end{array}$ \\
\hline Previous Effort & $\begin{array}{l}0.235 \\
(6.00)^{* * *}\end{array}$ \\
\hline Log Pseudo-likelihood & -501.455 \\
\hline \multicolumn{2}{|c|}{$*, * *, * * *$ Indicate 10 percent, 5 percent, and 1 percent significance, respectively. } \\
\hline \multicolumn{2}{|c|}{$\begin{array}{l}\text { Variable Definitions: } \\
\text { Effort }=\text { the dependent variable in this regression coded as } 1,2 \text {, or } 3 \text { for low, medium, and high, respectively; } \\
\text { Cheap Talk = a dummy variable equal to } 1 \text { if the worker has the ability to communicate his/her promised effort, and } 0 \\
\text { otherwise; } \\
\text { Multi-Period }=\text { a dummy variable equal to } 1 \text { if the worker and manager are paired for the entire experiment, and } 0 \\
\text { otherwise; } \\
\text { Cheap Talk } \times \text { Multi-Period }=\text { the interaction term of Cheap Talk and Multi-Period; } \\
\text { Wage = the wage offered to the worker from the manager; } \\
\begin{array}{l}\Delta \text { Wage }=\text { (Wage }- \text { Prior Period's Wage)/Prior Period's Wage; and } \\
\text { Previous Effort }=\text { the effort provided in the prior period. }\end{array}\end{array}$} \\
\hline
\end{tabular}

\section{Model 3:}

Deviation from Promised Effort $=\beta_{1}$ Wage $+\beta_{2} \Delta$ Wage $+\beta_{3}$ Promise $+\beta_{4}$ Period

$$
\begin{aligned}
& +\beta_{5} \text { Late Period }+\beta_{6} \text { Previous Effort }+\beta_{7} \text { Ethical } \\
& +\beta_{8} \text { Fairness }+\beta_{9} \text { Gift Exchange, }
\end{aligned}
$$

where Deviation from Promised Effort is the difference between the level of promised effort and the actual level of effort provided by the worker. ${ }^{9}$ In addition to the previous variables in Model 2 , Model 3 contains three exit questionnaire variables intended to capture workers' perceptions of ethical concerns (Ethical), the fairness of wages offered by the manager (Fairness), and their obligation to reciprocate higher effort for a higher wage (Gift Exchange). The variable Ethical is the response to the following item on the exit queide a different effort level during production." The variable Fairness is the response to the following item on the exit questionnaire: "In a given period, the wages offered to me by the manager were generally fair." Finally, the variable Gift Exchange is the response to the following item on the exit questionnaire: "When the manager offered a higher wage, I felt compelled to provide higher effort for production." Participants responded to these

\footnotetext{
${ }^{9}$ In seven periods (1.2 percent of accepted periods), the promised effort was lower than the actual effort provided. Setting the deviation from promised effort to 0 for these observations or removing them from the sample does not qualitatively change our results.
} 


\section{TABLE 6}

\section{Results of Ordered Probit Regressions of Effort in the Presence of Cheap Talk (with Clustered Error Terms)}

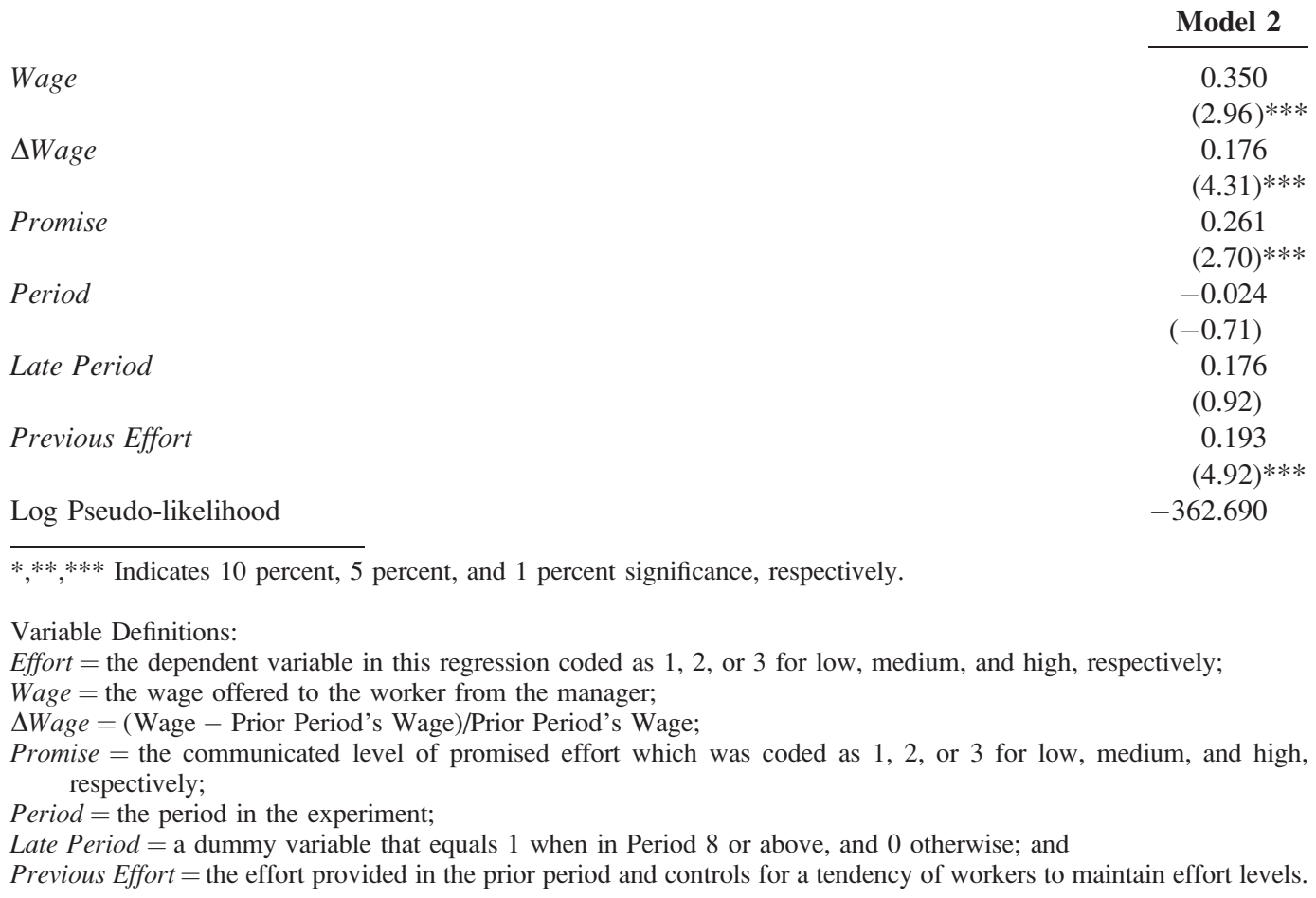

items on a Likert scale from 1 -Strongly Disagree to 7 -Strongly Agree, with 4 being Neutral. The variable Ethical is coded as $-1,0$, and 1 for low (1-2 on the Likert scale), medium (3-5 on the Likert scale), and high (6-7 on the Likert scale), respectively. ${ }^{10}$

The results of Model 3 are presented in Table 7. Interestingly, we find evidence of gift exchange behavior influencing the likelihood of keeping one's promise. The coefficients on Wage $\left(\beta_{1}\right)$ and $\Delta$ Wage $\left(\beta_{2}\right)$ are negative and significant $(\mathrm{p}<0.01)$. These results suggest that the higher the wage offered by the manager, the more likely it was for the worker to follow through on his/her promised effort. All of the exit questionnaire items are negative and significant (Ethical and Fairness $\mathrm{p}<0.05$, and Gift Exchange $\mathrm{p}<0.01)$. These results suggest that workers followed through on their promised level of effort, in part due to ethical concerns, perceptions of a fair wage, and the obligation to reciprocate with higher effort for a higher wage. Of particular relevance to Bicchieri's (2006) theory of social norm activation, the significance of the Ethical variable provides direct evidence that the communication of promising effort activated the promise-keeping norm in agents. None of the period-related variables were significant in the regression.

\footnotetext{
${ }^{10}$ We thank a reviewer for recommending this transformation of our Ethical variable. This transformation is necessary as the presence of a promised effort level led to significant ethical concerns among all of our participants on average $($ mean $=4.90, \mathrm{p}<0.01$ ). We find this as additional corroborating evidence that the promised level of effort activated a promise-keeping norm in the participants.
} 


\section{TABLE 7}

\section{Results of Ordered Probit Regression of Deviation from Promised Effort in the Presence of Cheap Talk (with Clustered Error Terms)}

\begin{tabular}{lc} 
& Model 3 \\
\cline { 2 - 2 } Wage & -0.396 \\
WWage & $(-3.04)^{* * *}$ \\
Promise & -0.173 \\
& $(-3.61)^{* * *}$ \\
Period & 1.20 \\
& $(7.32)^{* * *}$ \\
Late Period & 0.023 \\
Previous Effort & $(0.72)$ \\
Ethical & -0.222 \\
Fairness & $(-1.09)$ \\
Gift Exchange & -0.091 \\
& $(-2.19)^{* *}$ \\
Log Pseudo-likelihood & -0.288 \\
& $(-2.33)^{* *}$ \\
& -0.133 \\
& $(-2.13)^{* *}$ \\
& -0.242 \\
& $(-5.01)^{* * *}$
\end{tabular}

*,**,*** Indicate 10 percent, 5 percent, and 1 percent significance, respectively.

The dependent variable in this regression is the deviation from the promised effort level, which is the difference between the promised level of effort and the actual level of effort provided by the worker, where effort is coded as 1,2 , or 3 for low, medium, and high, respectively.

Participants responded to an exit questionnaire using a Likert scale from 1-Strongly Disagree to 7-Strongly Agree, with 4 being Neutral.

Variable Definitions:

Wage $=$ the wage offered to the worker from the manager;

$\Delta$ Wage $=($ Wage - Prior Period's Wage $) /$ Prior Period's Wage;

Promise $=$ the communicated level of promised effort which was coded as 1, 2, or 3 for low, medium, and high, respectively;

Period $=$ the period in the experiment;

Late Period = a dummy variable that equals 1 when in Period 8 or above, and 0 otherwise;

Previous Effort $=$ the effort provided in the prior period;

Ethical $=$ the response to the following item on the exit questionnaire: "It was unethical for a worker to contract for one effort level with the manager but provide a different effort level during production" coded as $-1,0$, and 1 , for low (1-2 Likert response), medium (3-5 Likert response), and high (6-7 Likert response), respectively;

Fairness $=$ the response to the following item on the exit questionnaire: "In a given period, the wages offered to me by the manager were generally fair"; and

Gift Exchange= the response to the following item on the exit questionnaire: "When the manager offered a higher wage, I felt compelled to provide higher effort for production."

We additionally ran a series of regressions with clustered error terms to determine the extent to which the wage offered by managers (Wage) was influenced by the worker's pre-contract communication of promised effort (Promise). In untabulated results, we find that the coefficient on the variable Promise is positive and highly significant $(\mathrm{p}<0.01)$ in all regression models of Wage. This result is robust to model specifications that include variables such as Period, Late Period, Previous Effort, Previous Wage, Period $*$ Promise, and Late Period $*$ Promise. Thus, the highly 
significant influence of the promised level of effort on Wage is a persistent result that does not change over time. This persistent result provides strong evidence that managers trusted the communication of promised effort as a promise that the worker would be motivated to keep, consistent with the social norm of promise-keeping. Thus, this result provides direct evidence that the communication of promised effort activated a promise-keeping norm in principals as well as agents.

\section{CONCLUSION}

We study the ability of cheap talk on the part of the agent to mitigate agency problems in the presence of a very noisy performance measure. Organizational settings can frequently contain very noisy performance measures, including non-profit settings (Rose-Ackerman 1996) and settings where skill and creativity are a large component of output such as with accountants, lawyers, engineers, and academics (Kachelmeier et al. 2008; Stevens and Thevaranjan 2010). The indirect or poorly understood relation between effort and output in such organizational settings makes it very difficult to arrange an efficient incentive contract. In many single- and multi-period agency settings in the firm, however, the agent can communicate a promised level of effort to the principal prior to contracting. We document that this pre-contract communication, which is non-enforceable and therefore considered "cheap talk" by traditional economic theory, can be highly effective in mitigating agency problems in a single-period and multi-period setting. In a repeating single-period experimental setting, where production is observable but is a very noisy indicator of effort, communication of a promised level of effort results in higher pay for the agent, higher effort, and higher profit for the principal than the control group. When the principal and agent interact over multiple periods, reputation building is ineffective, but cheap talk continues to yield superior outcomes.

These findings should be of interest to researchers, managers, and policy makers. Our results are consistent with recent economic theory incorporating social norms (Mittendorf 2006; Fischer and Huddart 2008; Stevens and Thevaranjan 2010). For example, our results support the principal-agent model in Stevens and Thevaranjan (2010), which incorporates some level of moral sensitivity on the part of the agent that allows the principal to rely on a previously agreed-upon level of effort. Consistent with their model, we find that a promised level of effort allows the principal and agent to engage in incremental gift exchange behavior that benefits both parties. Our results also support Bicchieri's (2006) model of social norm activation. Consistent with her model, we find evidence that the communication of promised effort by the agent activates the promise-keeping norm in both the agent and the principal, leading to promise-keeping behavior in the agent and trusting behavior in the principal. Thus, our study contributes to the management accounting literature by demonstrating the effectiveness of the promise-keeping norm in a principal-agent setting and the ability of cheap talk on the part of the agent to activate this social norm.

Our main result, that the agent's communication of a promised level of effort is effective at mitigating agency problems in the presence of a very noisy performance measure, should be good news to managers and policy makers. Noisy performance measures not only make traditional incentive solutions prohibitively expensive, they also make reputation building over multiple periods very difficult, as output provides limited information on effort. Thus, pre-contract communication of promised effort on the part of the agent may be an important part of organizational control that has not been previously recognized in the literature. Our results contribute to the extensive experimental literature in economics documenting that participants frequently exhibit "repeated play behavior" in single-period settings and achieve cooperative solutions that surpass game theoretic predictions based on narrow self-interest. To help explain this behavior, economists have incorporated the concept of "ecological" rationality that takes socially 
derived rules and norms into consideration (Smith 2010). Economists have also found references to this alternative form of rationality in the writings of Adam Smith (1759/1966). Our study provides further evidence of this alternative form of rationality based on social norms. Our results also contribute to the experimental literature in management accounting examining alternative solutions to agency problems in the firm (Brown et al. 2009).

Our results contribute to several other streams of experimental research in management accounting. In particular, our results contribute to the experimental literature documenting social norms for honesty in participative budgeting settings (Evans et al. 2001; Stevens 2002; Hannan et al. 2006; Rankin et al. 2008; Hobson et al. 2011) and the experimental literature documenting gift exchange behavior (Hannan 2005; Kuang and Moser 2009). Our results suggest that allowing the agent to provide a pre-contract communication of promised effort activates the social norm of promise-keeping in both the principal and the agent. Thus, our study not only adds to the list of social norms that may be relevant in an organizational setting, our study also provides evidence that such social norms can be activated by situational cues. Finally, our study contributes to the gift exchange literature by showing that the social norm of promise-keeping can generate incremental gift exchange behavior that is profitable to both the principal and the agent. This result is important because the gift exchange literature is largely silent on when gift exchange behavior will occur and whether it will be profitable to the firm. Consistent with Stevens and Thevaranjan's (2010) principal-agent model, our results suggest that the principal will engage in gift-exchange behavior if it is profitable for the firm to induce more than a minimal level of effort, and the moral sensitivity of the agent will allow the principal to profit from such gift-exchange behavior.

\section{REFERENCES}

Akerlof, G. 1982. Labor contracts as partial gift exchange. Quarterly Journal of Economics 97: 543-569.

Baiman, S. 1982. Agency research in management accounting. Journal of Accounting Literature 1: 154213.

Baiman, S. 1990. Agency research in managerial accounting: A second look. Accounting, Organizations and Society 15 (4): 341-371.

Bicchieri, C. 2006. The Grammar of Society: The Nature and Dynamics of Social Norms. New York, NY: Cambridge University Press.

Brandts, J., and D. Cooper. 2006. A change would do you good: An experimental study on how to overcome coordination failure in organizations. American Economic Review 96 (3): 669-693.

Brandts, J., and D. Cooper. 2007. It's what you say, not what you pay: An experimental study of manageremployee relationships in overcoming coordination failure. Journal of the European Economic Association 5 (6): 1223-1268.

Brown, J., J. Evans, and D. Moser. 2009. Agency theory and participative budgeting experiments. Journal of Management Accounting Research 21: 317-345.

Evans, J., R. Hannan, R. Krishnan, and D. Moser. 2001. Honesty in managerial reporting. The Accounting Review 76 (4): 537-559.

Farrell, J. 1987. Cheap talk, coordination, and entry. Rand Journal of Economics 18 (Spring): 34-39.

Farrell, J. 1993. Meaning and credibility in cheap-talk games. Games and Economic Behavior 5 (October): $514-531$.

Fischbacher, U. 2007. z-Tree: Zurich toolbox for ready-made economic experiments. Experimental Economics 10 (2): 171-178.

Fischer, P., and S. Huddart. 2008. Optimal contracting with endogenous social norms. American Economic Review 98: 1459-1475.

Fisher, J., S. Peffer, G. Sprinkle, and M. Williamson. 2008. Reciprocity, Repeated Play, and Budget-Based Contracts. Working paper, Indiana University. 
Hannan, R. 2005. The combined effect of wages and firm profit on employee effort. The Accounting Review 80 (1): $167-188$.

Hannan, R., J. Kagel, and D. Moser. 2002. Partial gift exchange in an experimental labor market: Impact of subject population differences, productivity differences, and effort request on behavior. Journal of Labor Economics 20 (4): 923-951.

Hannan, R., F. Rankin, and K. Towry. 2006. The effect of information systems on honesty in managerial reporting: A behavioral perspective. Contemporary Accounting Research 23: 885-915.

Hobson, J., M. Mellon, and D. Stevens. 2011. Determinants of moral judgments regarding budgetary slack: An experimental examination of pay scheme and personal values. Behavioral Research in Accounting 23 (1): 87-107.

Jackson, D. 1994. Jackson Personality Inventory-Revised Manual. Port Huron, MI: Sigma Assessment Systems, Inc.

Kachelmeier, S., B. Reichert, and M. Williamson. 2008. Measuring and motivating quantity, creativity, or both. Journal of Accounting Research 46 (2): 341-374.

Kachelmeier, S., J. Smith, and W. Yancey. 1994. Budgets as a credible threat: An experimental study of cheap talk and forward induction. Journal of Management Accounting Research 6: 144-174.

Kuang, X., and D. Moser. 2009. Reciprocity and the effectiveness of optimal agency contracts. The Accounting Review 84 (5): 1671-1694.

Lambert, R. 2001. Contracting theory and accounting. Journal of Accounting and Economics 32: 3-87.

Miller, G. 1992. Ethics and the new game theory. In Ethics and Agency Theory: An Introduction, edited by Bowie, N., and E. Freeman. New York, NY: Oxford University Press.

Mittendorf, B. 2006. Capital budgeting when managers value both honesty and perquisites. Journal of Management Accounting Research 18: 77-95.

Prendergast, C. 1999. The provision of incentives in firms. Journal of Economic Literature 37 (1): 7-63.

Rankin, F., S. Schwartz, and R. Young. 2003. Management control using non-binding budgetary announcements. Journal of Management Accounting Research 15: 75-93.

Rankin, F., S. Schwartz, and R. Young. 2008. The effect of honesty and superior authority on budget proposals. The Accounting Review 83 (4): 1083-1099.

Rose-Ackerman, S. 1996. Altruism, non-profits, and economic theory. Journal of Economic Literature 34 (2): 701-728.

Schatzberg, J., and D. Stevens. 2008. Public and private forms of opportunism within the organization: A joint examination of budget and effort behavior. Journal of Management Accounting Research 20: $59-81$.

Smith, A. 1759/1966. The Theory of Moral Sentiments. Reprints of Economic Classics. New York, NY: A.M. Kelley.

Smith, V. 2010. Rationality in Economics: Constructivist and Ecological Forms. New York, NY: Cambridge University Press.

Stevens, D. 2002. The effects of reputation and ethics on budgetary slack. Journal of Management Accounting Research 14: 153-171.

Stevens, D., and A. Thevaranjan. 2010. A moral solution to the moral hazard problem. Accounting, Organizations and Society 35: 125-139. 
Copyright of Journal of Management Accounting Research is the property of American Accounting Association and its content may not be copied or emailed to multiple sites or posted to a listserv without the copyright holder's express written permission. However, users may print, download, or email articles for individual use. 